Cell Research (1993),3, 93-101

\title{
Mitosis and microtubule organizational changes in rice root-tip cells
}

\author{
XU Shixiong (SY ZEE) $)^{1^{*}}, C_{\text {hungui LI** }}{ }^{* *}$ Cheng \\ ZHU** \\ *Botany Department, HongKong University, \\ **Department of Biology, Peking University, Beijing \\ 100871, China.
}

\begin{abstract}
The pattern of change of the microtubule cytoskeleton of the root-tip cells of rice during mitosis was studied using immunofluorescence technic and confocal laser scanning microscopy. All the major stages of cell division including preprophase, prophase, metaphase, anaphase and telophase were observed. The most significant finding was that in the preprophase cells microtubules radiating from the nuclear surface to the cortex were frequently seen. During development these microtubules became closely associated with the preprophase band and prophase spindle indicating that the microtubules radiating from the nuclear surface, the preprophase band and the prophase spindle were structurally and functionally closely related to each other. Granule-like anchorage sites for the radiating microtubules at the nuclear surface were often seen and the possibility that these granule-like anchorage sites might represent the microtubule organizing centres was discussed.
\end{abstract}

Key words: microtubule, mitosis, preprophase, root cells, Oryza sativa.

\section{INTRODUCTION}

Mitosis in higher plants has been studied by a large number of workers for a long period of time[1-13]. But in spite of the large number of papers published on the subject the mechanisms of mitosis and the transition between various microtubule arrays during mitosis in higher plant cells are still poorly understood. In the study

1. Corresponding author. 
Mitosis and microtubule organizational changes in rice root-tip cells

of higher plant mitosis, root-tip cells have often been used[14-20]. But as far as we are aware mitosis in the root-tip cells of rice has not yet been studied using such modern techniques such as immunofluorescence and confocal laser scanning microscopy. Thus it is the purpose of this study to unravel as far as possible the pattern of organizational changes of the microtubule cytoskeleton during root-tip cell mitosis using immunofluorescence and confocal laser scanning microscopy.

\section{MATERIALS AND METHODS}

Seeds of Oryza sativa L. cv. Qigui Zao were germinated in Petri dishes on moist filter papers. After the roots had reached a length of about 2-3 cm the root tips were removed and fixed according to the method described by McCurdy and Gunning[17].

Immunofluorescence labelling was carried out with anti- $\alpha$-tubulin(Sigma T-9026) (1:500) and anti-mouse-FITC(Sigma F-02571)(1:16). All incubations were performed at $37^{\circ} \mathrm{C}$ for 40 mins, followed by three $10 \mathrm{mim}$ washes with PBS. Controls were done using only the second antibody and they showed no labelling.

Confocal laser scanning microscopy was carried out using a Bio-Rad MRC-600 confocal microscope with BHS filters. The images were contrast enhanced before recorded on Kodak TMAX-100 films.

\section{RESULTS}

\section{Preprophase}

For ease of description the changes in the organizational pattern of the microtubules in the preprophase cells has been divided into five categories according to the shape and form of the preprophase band[17].

\section{Category I}

The microtubule cytoskeleton in the Category I cells consists of a file of cortical microtubules that lie parallel to each other and transverse to the direction of cell elongation (Fig 1). This array of parallel microtubules usually spread throughout the entire width of the cell. No perinuclear microtubules appear to be present in the Category I cells.

\section{Category II}

Cells in this category possess a wide preprophase band which usually covers the whole region of the cell surface (Fig 2A). Some microtubules begin to form radiating from the surface of the nucleus towards the cell cortex (Fig 2B). Some of the radiating microtubules also possess a granule-like head at the point of attachment between the microtubules and the nuclear surface.

\section{Category III}

In this category the preprophase band becomes narrower. Constituent microtubules (or bundles of microtubules) are still obvious (Fig 3A). Some of the micro- 
tubules radiating from the nucleus become associated with the preprophase band (Fig 3B).

\section{Category IV}

In this category individual microtubules are often difficult to discern in the preprophase band due to the close packing of individual microtubules. Microtubules radiating from the nuclear region towards the preprophase band are now more abundant (Fig 4). Some microtubules appear to form a layer around the nucleus (Fig 5). Some of the nuclear microtubules have granule-like heads associated with them.

\section{Category $V$}

In this category the preprophase band can still be seen. Microtubules radiating from the nucleus and associating with the preprophase band (Fig 6A, B) are still very abundant. In a position perpendicular to the plane of the preprophase band (or the division plane) some microtubules surrounding the nucleus are seen converging into a prophase spindle(Fig $6 \mathrm{~A}, \mathrm{~B}, 7)$.

\section{Prophase}

The prophase cells are characterized by the absence of the preprophase band (Fig 8). But they possess numerous randomly distributed microtubules in the cytoplasm. At late prophase, after the break down of the nuclear envelope the general pattern of distribution of the microtubules dose not change much.

\section{Metaphase}

At metaphase the chromosomes become aligned at the spindle equator. In order to visualize the chromosomes the sections have been immunofluorescently labelled with BNS-I(Fig 9) (BNS-1 will only react with the chromosomes[Zee, unpublished data]).

\section{Anaphase}

At anaphase A chromosomes start to separate and interzone microtubules appear (Fig 10). Later, at anaphase B interzone microtubules elongate (Fig 11) pushing sister chromosomes farther apart.

\section{Telophase}

At early telophase phragmoplast microtubules begin to form (Fig 12). But soon afterwards the phragmoplast microtubules in the cell centre begin to disappear (Fig 13). Later, the phragmoplast microtubules at the periphery also disappear. The two new daughter cells then become filled with randomly distributed microtubules. In some cells the perinuclear microtubules in some daughter cells reform(Fig 14). 
Mitosis and microtubule organizational changes in rice root-tip cells

But in others they do not seem to reform(Fig 15).

\section{DISCUSSION}

The classification of the preprophase into different stages of development is quite arbitrary. McCurdy and Gunning (1990). [17] and Gunning and Sammut (1990) [20] found it convenient to divide the developmental stages of the preprophase into five categories based on the structure of the preprophase band. But Wang et al (1989)[21], found it more convenient to divide the preprophase into six developmental stages based on the state of condensation of the chromosomes. In the root-tip cells of rice we found it convenient to divide the preprophase also into five categories using the classification method of McCurdy and Gunning (1990) [17]. It was extremely difficult to use the state of the condensation of the chromosomes to make classification because the staining of the chromosomes with either Hoechest-33258 or DAPI often failed to reflect the state of condensation of the chromosomes.

In the preprophase cells of rice studied here we have shown the existence of nucleoassociated microtubules at a number of developmental stages. The distribution and function of the nucleo-associated microtubules have recently attracted a lot of attention[22-24]. Flanders et sl (1990) [25] showed that in the epidermal cells of Datura stramonium the microtubules radiating from the nucleus are involved in the earliest stages of cortical array formation. In a later study Lloyd et al (1991) [23] revealed that in the epidermal cells of Nantilocalyx lynchii "the nucleus associated microtubules are a major component of the phragmosome, that they change from a radiating to a planar distribution concomitantly with the 'bunching' of cortical microtubules to form the preprophase band". In the root-tip cells of rice studied here we have shown for the first time that the microtubules radiating fom the nucleus are not only attached to the preprophase band but they are also attached to the prophase spindle indicating that the microtubules radiating from the nucleus may play an important role in controlling the organization of the preprophase band and the prophase spindle.

Lambert et al(1992) [13] and Xu et al (1992)[26] have provided evidence to show that multiple microtubule anchorage (or organizing or nucleating) sites or foci (i.e. the granule-like structure of the radiating microtubules) similar to those seen in the root-tip cells of rice are present on the nuclear surface of Haemanthus endosperm cell and Narcissus pollen using immuno-labelling techniques. Chevrier et al (1992)[27] have provided further evidence to show that the foci around the nuclear envelope may indeed be microtubule organizing centers. Although evidences are now accumulating indicating that the granule-like structure associated with radiating microtubule from the nucleus may represent a microtubule organizing centre but unfortunately up till now we are still unsure of its fine structure. 


\section{REFERENCES}

[1] Gunning BES, Hardham AR. Microtubules. Ann Rev Plant Physiol 1982; 33:651-98.

[2] Hepler PK. The plant cytoskeleton. In: Robards AW, ed. Botanical Microscopy. Oxford University Press: Oxford New York Tokyo 1985: 233-62.

[3] Gunning BES, Wick SM. Preprophase bands, phragmoplasts, and spatial control of cytokinesis. J Cell Sci 1985; Suppl. 2:159-79.

[4] Bajer AS, Mole-Bajer J. Reorganization of microtubules in endosperm cells and cell fragments of the higher plant Haemanthus in vivo. J Cell Biol 1986; 102:263-81.

[5] Seagull RW. The plant cytoskeleton. Critical Reviews in Plant Sciences 1989;8 (2):131-67.

[6] Baskin TI, Cande WZ. The structure and function of the mitotic spindle in flowering plants. Annu Rev Plant Physiol Plant Mol Biol 1990; 41:277-315.

[7] Zhang D, Wadsworth P, Hepler PK. Microtubule dynamics in living dividing plant cells: confocal imaging of microinjected fluorescent brain tubulin. Proc Natl Acad Sci USA 1990; 87:8820-24.

[8] Staiger C J, Lloyd CW. The plant cytoskeleton. Cytoplasm and cell motility 1991; 3:33-42.

[9] Wang H, Cutler A J, Fowke LC. Microtubule organization in cultured soybean and black spruce cells: interphase-mitosis transtion and spindle morphology: Protoplasma 1991; 162:46-54.

[10] Fowke LC, Attree SM, Wang H, Dunstan DI. Microtuble organization and cell division in embryogenic protoplast cultures of white spruce (Picea glauca). Protoplasma 1990; 138:86-94.

[11] Wick SM. The preprophase band. In: Lloyd CW ed. " The Cytoskeletal Basis of Plant Growth and Form". Academic Press. 1991: 231-44.

[12] Hasezawa S, Nagata T. Dynamic organization of plant microtubules at the three distinct transition points during the cell cycle progression of synchronized tobacco BY-2 cells. Bot Acta 1991; 104:206-11.

[13] Lambert AM, Vantard M, Schmit AC, Stoeckel H. Mitosis in plants. In: Lloyd CW ed. "The Cytoskeletal Basis of Plant Growth and Form". Academic Press. 1991: 199-208.

[14] Wick SM. Immunofluorescence microscopy of tubulin and microtubule arrays in plant cells. III. Transition between mitotic/cytokinetic and interphase microtubule arrays. Cell Biology International Reports 1985; 9(4):357-71.

[15] Wick SM. The higher plant mitotic apparatus: redistribution of microtubules, calmodulin and microtubule initiation material during its establishment. Cytobios 1985; 43:285-94.

[16] Kubiak J, De Brabander M, De Mey J, Tarkowska JA. Origin of the mitotic spindle in onion root cells. Protoplasma 1986; 130:51-6.

[17] McCurdy DW, Gunning BES. Reorganization of cortical actin microfilaments and microtubules at preprophase and mitosis in wheat root- tip cells: a double label immunofluorescence study. Cell Motility and the Cytoskeleton 1990; 15:76-87.

[18] Panteris E, Galatis B, Apostolakos P. Patterns of cortical and perinuclear microtubule organization in meristematic root cells of Adiantum capillus veneris. Protoplasma 1991; 165:173-88.

[19] Wick SM, Duniec Jadwiga. Immunofluorescence microscopy of tubulin and microtubule arrays in plant cells. II. Transition between the preprophase band and the mitotic spindle. Protoplasma 1984; 122:45-55.

[20] Gunning BES, Sammut M. Rearrangments of microtubules involved in establishing cell division planes start immediately after DNA synthesis and are completed Just before mitosis. The Plant Cell 1990; 2:1273-82.

[21] Wang H, Cutler A J, Fowke, LC. High frequencies of preprophase bands in soybean protoplast cultures. J Cell Sci 1989; 92:575-80.

[22] Dickinson HG, Sheldon JM. A radial system of microtubules extending between the nuclear envelope and the plasma membrane during early male haplophase in flowering plants. Planta 1984; 161:86-90.

[23] Lloyd CW. Cytoskeletal elements of the phragmosome establish the division plane in vacuolated higher plant cells. In: Lloyd CW ed. "The Cytoskeletal Basis of Plant Growth and Form". 
Mitosis and microtubule organizational changes in rice root-tip cells

Academic Press 1991:245-57.

[24] Lloyd CW, Venverloo CJ, Goodbody KC. Confocal laser microscopy and three-dimensional reconstruction of nucleus-associated microtubules in the division plane of vacuolated plant cells. J Microscopy 1992; 166:99-109.

[25] Flanders DJ, Rawlins DJ, Shaw PJ, Lloyd CW. Re-establishment of the interphase microtubule array in vacuolated plant cells, studied by confocal microscopyand. 3-D imaging. Development 1990; 110:897-904.

[26] Xu SH, Li CG, Zhu C. Confocal microscopy of microtubule cytoskeleton in the pollen protoplast of Narcissus. Acta Botanica Sinica 1992(in prss).

[27] Chevrier V, Komesli S, Schmit A-C, Vantard M, Lambert A-M, Job Didier. A monoclonal antibody, raised against mammalian centrosomes and screened by recognition of plant microtubule organizing centers, identifies a pericentriolar component in different cell types. J Cell Sci 1992; 101:823-35.

Received 17-8-1992. Revised 28-9-1992. Accepted 28-10-1992.

\section{Explanation of figures}

Using the Argon ion laser of the confocal microscope it is not possible to image the Hoechst stained chromosomes: So in the photographs presented below the chromosomes appear as dark regions. Except for Fig 9 where the chromosomes have been counter stained using a chromosome specific BNS-1 monoclonal antibody-FITC conjugate.

\section{Plate I}

Fig 1. A Category I preprophase cell containing a parallel array of microtubules.

Fig 2A, B. Two optical sections of a Category II preprophase cell. A broad preprophase band is beginning to from in this cell (Fig 2A). At this stage microtubules radiating form the nuclear surface also start to appear (Fig 2B, arrow). $\mathrm{N}=$ nucleus.

Fig 3A, B Two optical sections of a Category III preprophase cell. Note that the preprophase band $(\mathrm{P})$ is narrowing and microtubules radiating from the nuclear surface are connected to the preprophase band (Fig 3B, arrow): $\mathrm{N}=$ nucleus.

Fig 4. A Category IV preprophase cell. Note the close association of the radiating microtubules from the nuclear surface [containing a granulelike anchorage site (arrow)] with the preprophase band $(\mathrm{P}) . \mathrm{N}=$ nucleus.

Fig 5. Another view of a Category IV preprophase cell showing some microtubules forming a layer (arrow) around the nucleus $(\mathrm{N}) . \mathrm{P}=$ preprophase band. 
Xu SX et al.
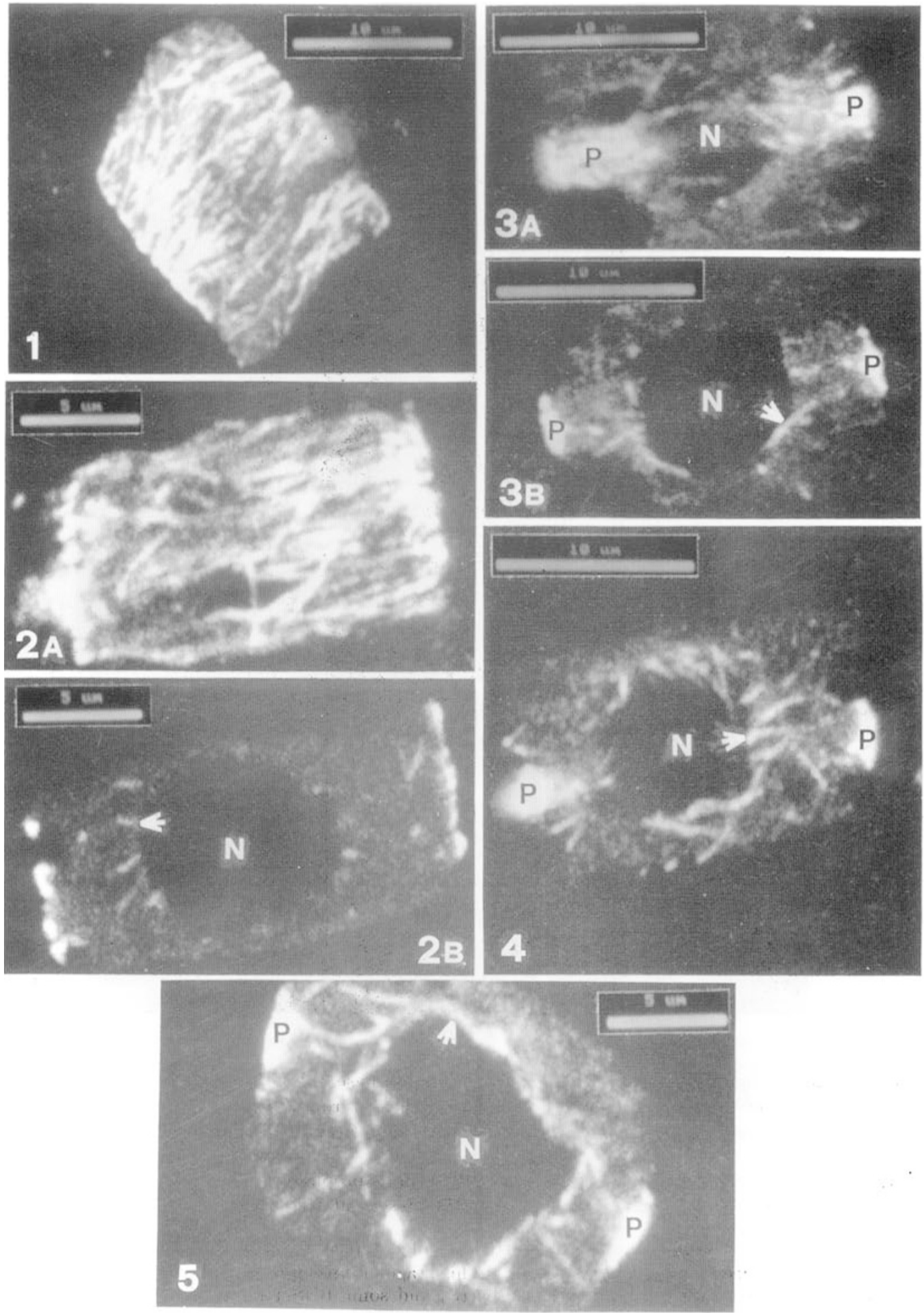
Mitosis and microtubule organizational changes in rice root-tip cells
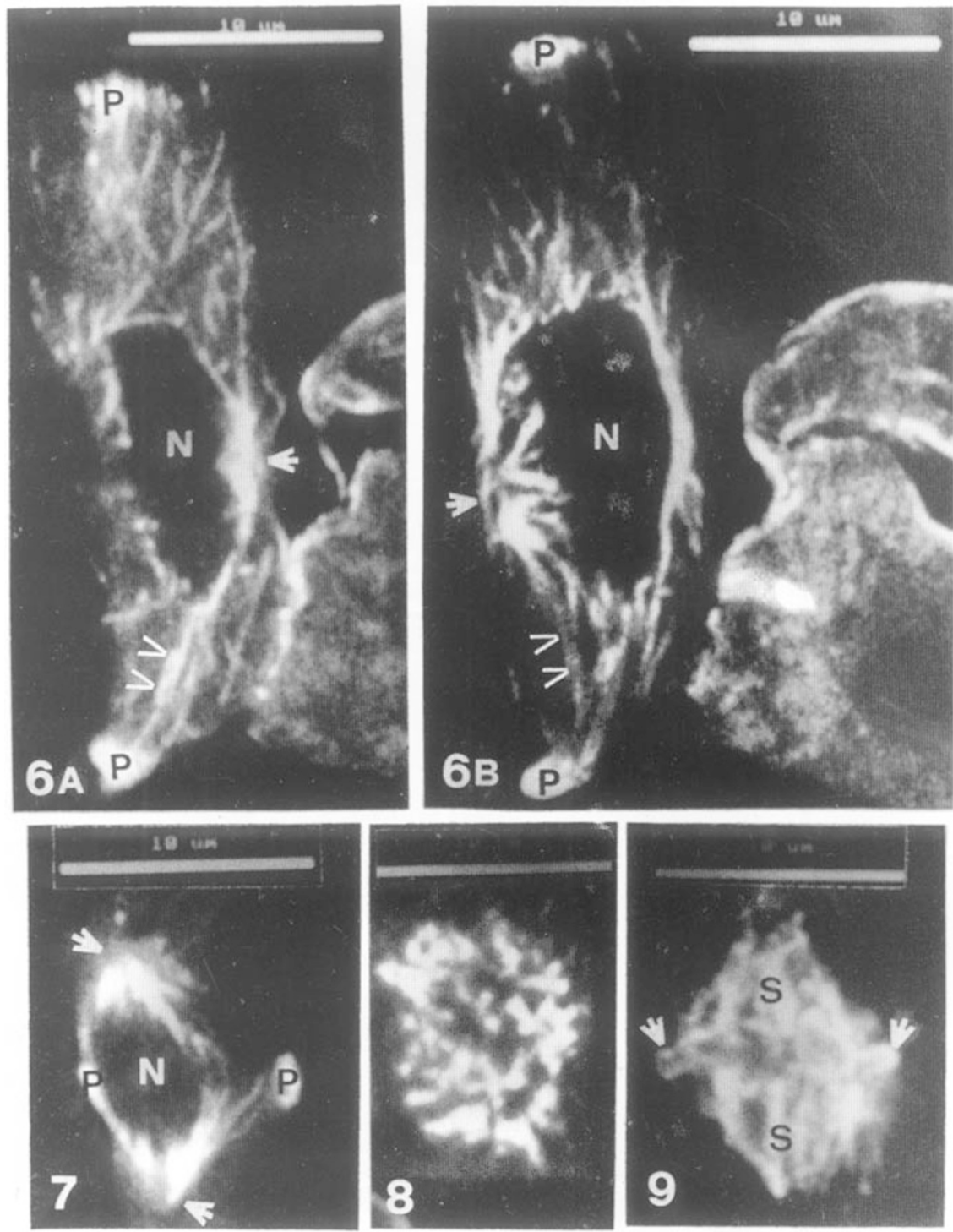

Plate II

Fig 6A, B. Two optical sections of a Category V preprophase cell. Note the close association of the radiating microtubules (arrow head) from the nuclear surface with the preprophase band $(\mathrm{P})$. Note also the formation of the prophase spindle (arrow).

Fig 7. A late Category V preprophase cell showing a prophase spindle (arrow). Note that the preprophase band $(\mathrm{P})$ is still present at this stage of development. $\mathrm{N}=$ nucleus.

Fig 8. An optical section at the mid region of a typical prophase cell. Note the absence of a preprophase band at this stage of development of the cell.

Fig 9, A metaphase cell showing spindle (S) and some BNS-1 immunofluorescently labelled chromosomes (arrows). 
Xu SX et al.
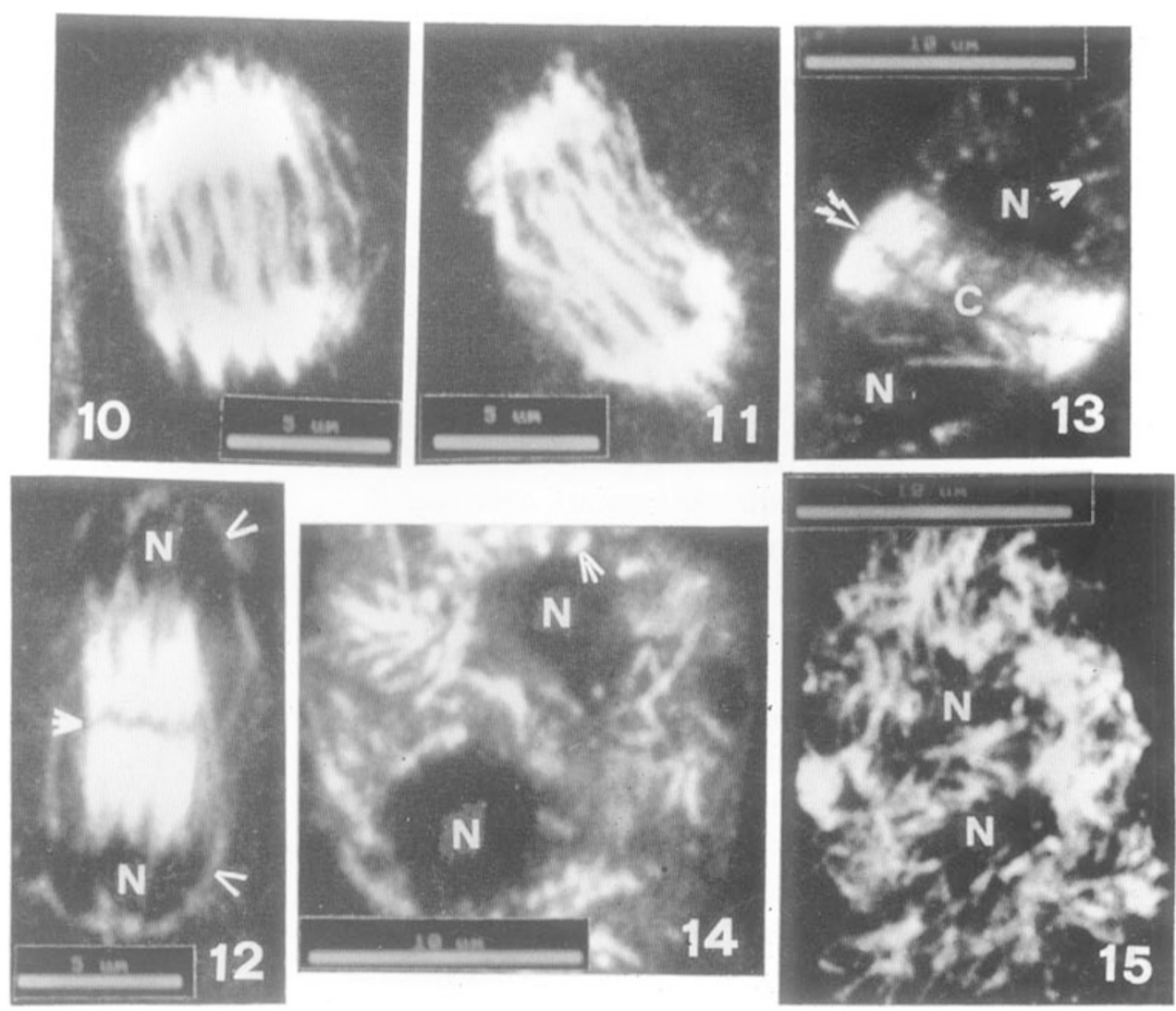

\section{Plate III}

Fig 10. An anaphase A cell. The dark areas are chromosomes and the bright areas are microtubules.

Fig 11. An anaphase B cell. The dark areas are chromosomes and the bright areas are microtubules.

Fig 12. An early telophase cell showing a phragmoplast (arrow) and its associated microtubules. Note that the peripheral region of the daughter nuclei is still surrounded by some spindle microtubules (arrow head). $\mathrm{N}=$ nucleus.

Fig 13. A mid-telophase cell showing phragmoplast microtubules beginning to disappear in the cell centre (C). At this stage radiating microtubules from the nuclear surface start to form (arrow). Black/white arrow=phragmoplast; $\mathrm{N}=$ nucleus

Fig 14. A late telophase cell showing two daughter nuclei $(\mathrm{N})$. Arrow=granule-like anchorage site of microtubules at the nuclear surface(arrow).

Fig 15. Telophase-interphase transition. Radiating microtubules from the nuclear surface are no longer present and the cytoplasm of the daughter cells is filled with numerous randomly oriented microtubules. 